\title{
A Case Report of Blepharotosis as a Complication of Endoscopic Sinus Surgery
}

\author{
Hwikyeong Jung, Geonwoo Kim, Jaesoon Kim, and Kyubo Kim $\mathbb{B}$ \\ Department of Otorhinolaryngology-Head and Neck Surgery, Kangdong Sacred Heart Hospital, Seoul, Korea
}

\section{비내시경 부비동 수술 후 발생한 안검하수 1예}

정휘경 · 김건우 · 김재순 · 김규보

강동성심병원 이비인후-두경부외과

\author{
Received June 22,2020 \\ Revised July 15,2020 \\ Accepted July 22, 2020 \\ Address for correspondence \\ Kyubo Kim, MD, PhD \\ Department of Otorhinolaryngology- \\ Head and Neck Surgery, \\ Kangdong Sacred Heart Hospital, \\ Hallym University \\ College of Medicine, \\ 150 Seongan-ro, Gangdong-gu, \\ Seoul 05355 , Korea \\ Tel $+82-2-2225-2734$ \\ Fax $+82-2-482-2279$ \\ E-mail kyubo@kdh.or.kr
}

Endoscopic sinus surgery (ESS) is a common procedure performed in patients with chronic sinusitis. Although most of them result in excellent outcomes, some complications due to injury of nearby structures, such as the orbit or brain, may have serious consequences. Ophthalmic complications, occurring in less than $1 \%$ of all ESS cases, include orbital hematoma, diplopia, injury to the nasolacrimal duct, and in severe cases, even blindness. Here, we present a rare case in which a 49-year old female developed unilateral blepharoptosis after undergoing revision ESS.

Korean J Otorhinolaryngol-Head Neck Surg 2021;64(6):429-32

Key Words Blepharoptosis · Endoscopy $\cdot$ Reoperation $\cdot$ Sinusitis.

\section{서 론}

내시경 부비동 수술은 다양한 부비동 질환에 시행하는 흔 한 수술 방법이지만 안구와 뇌 등의 주요 구조와 매우 인접 하기 때문에 심각한 합병증이 발생할 수 있다. 내시경 부비동 수술 후 합병증은 크게 안와 합병증 및 두개 내 합병증으로 나눌 수 있다. ${ }^{1)}$ 내시경 부비동 수술 후 생긴 안와 합병증의 발생율은 $0.12 \sim 0.85 \%$ 로 보고자마다 다르며 ${ }^{2-5)}$ 대체로 내시경 부비동 수술의 $1 \%$ 미만에서 나타난다고 보고되고 있으며, 지 판손상, 안와혈종, 비루관 손상, 안구 내직근 손상, 시신경 손 상 등이 이에 해당된다. ${ }^{6-8)}$

내시경 부비동 수술 후 3번 뇌신경(동안신경)의 마비는 극 히 드문 합병증으로, 본 증례는 만성 부비동염 및 비용종 진

This is an Open Access article distributed under the terms of the Creative Commons Attribution Non-Commercial License (https://creativecommons.org/licenses/by-nc/4.0) which permits unrestricted non-commercial use, distribution, and reproduction in any medium, provided the original work is properly cited.
단 하에 내시경 부비동 재수술 시행 후 좌측 안검하수를 보 였던 환자에 대한 증례 보고와 발생 기전에 대해 고찰을 하 고자 한다. 본 연구는 본원의 연구윤리 심의 위원회의 심의 면제를 받았다(IRB No. 2020-06-005).

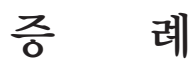

49세 여자 환자가 수년간 지속되는 점성 콧물을 주소로 본과 외래에 내원하였다. 과거 병력상 고혈압, 당뇨, 천식 치 료를 받고 있었으며 수년전에 발생한 뇌경색으로 항혈소판제 인 클로피도그렐 $75 \mathrm{mg}$ 을 복용 중이었다. 또한, 내원 약 10년 전 1차 의원에서 국소마취하 양측 부비동 수술 받은 적이 있 었다. 상기 증상으로 메틸프레드니솔론 $4 \mathrm{mg}$, 슈도에페드린 염산염 $120 \mathrm{mg}$-펙소페나딘염산염 $60 \mathrm{mg}$ 복합체, 록시트로 마이신 $150 \mathrm{mg}$ 을 2주간 복용하였으나 증상 호전이 없었다. 내원 당일에 시행한 내시경 소견상 양측 중비도 내 비용종이 

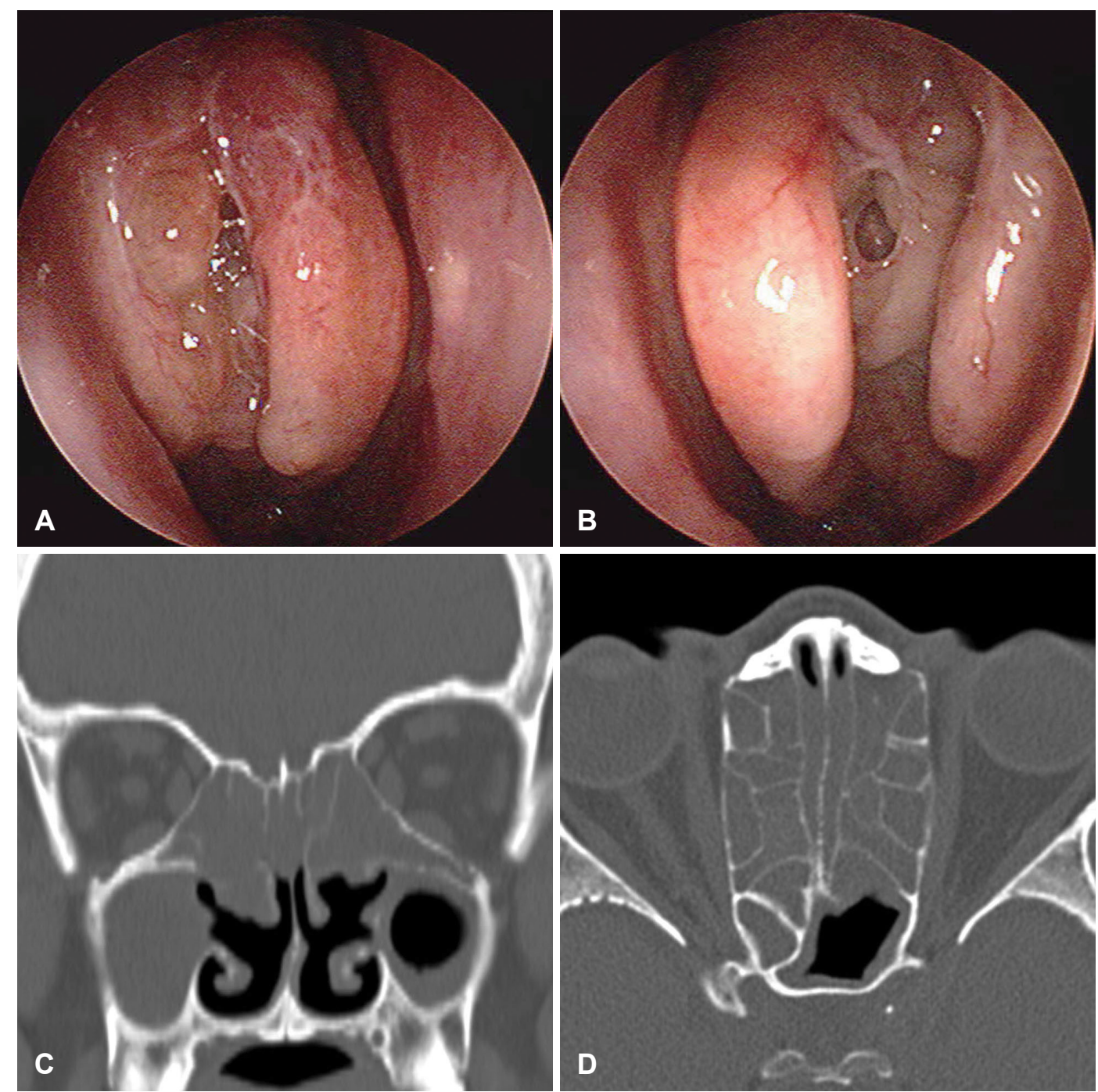

Fig. 1. Preoperative endoscopic and CT findings. Preoperative endoscopic findings of right (A) and left (B) nasal cavities show both nasal cavities were post-ethmoidectomy state with recurred polyps. Coronal view $(C)$ and axial view $(D)$ of preoperative nonenhanced paranasal CT showed pansinusitis.

관찰되었으며(Fig. 1A and B), 부비동 전산화단층촬영(computed tomography, CT)상에서 범부비동염 소견을 보여(Fig. $1 \mathrm{C}$ and D) 수술적 치료를 진행하였다. 수술 시행하기 5일 전 에 복용하던 항응고제를 중단하였다.

수술 당시 양측 비강은 부비동 수술 받은 후의 상태였으며 점막은 전반적으로 비용종성 양상을 보였다. 양측 비용종에 대해서는 미세흡입절삭기로 비용종 절제술을 시행하였으며 출혈로 인해 수술 시야 확보가 어려웠다. 좌측 상악동에서 점 액농성의 점도가 높은 분비물을 제거하였다. 좌측 사골동에 서 재수술 시행 중 후사골동에 지판 손상이 작게 있어 안구 지방이 일부 노출되었으나 다른 특이 소견은 뚜렷하게 보이 지 않아 양측 비강에 흡수성 패킹제제를 삽입 후 수술을 종 료하였다.
수술 마치고 두 시간 뒤 환자 좌측 안구 주위에 반상 출혈 및 경도의 부종이 있어 스테로이드 주사제를 투여하였다. 당 시 좌측 외안근 운동 장애도 뚜렷하게 보이지 않았다. 수술 후 1 일째 안구 부종이 호전되어 보였으나 수술 후 2일째 환자 가 좌측 안구 통증을 호소하였고 좌측 안구 주위 부종이 심 해졌으며 안검하수 소견도 관찰되어 시행한 안구 CT에서 좌 측 지판의 윗쪽 부분 손상 및 좌측 안와의 상내측 혈종이 관 찰되었다(Fig. 2). 시행한 안과 협진 상, 안와내 혈종으로 인 한 내직근의 유착 혹은 내직근 및 눈꺼풀올림근의 미세 손 상의 가능성이 있어 최소 6 개월 경과 관찰이 필요하므로 6 개 월 후 재평가하여 증상이 지속될 경우 수술적 교정을 하기로 했다. 수술 후 5일째부터 좌측 안구 주위 부종은 호전되는 양상이었으나 안검하수는 지속되었다(Fig. 3). 우측 및 좌측 

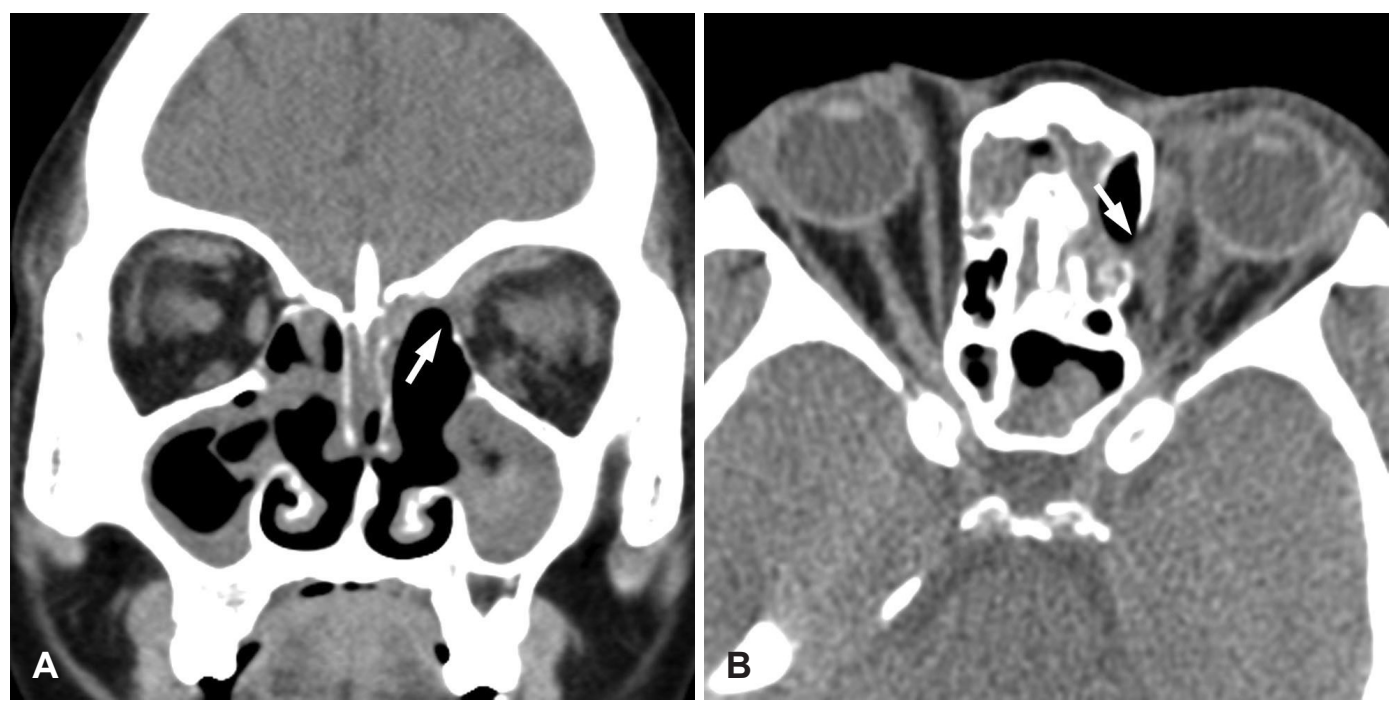

Fig. 2. Findings of postoperative CT taken two days after the surgery. Coronal view (A) and axial view (B) of nonenhanced orbit $C T$ showed a small bone dehiscence at the superior portion of the medial wall of the left orbit (arrow) and a small subperiosteal hematoma at the superior and medial aspect of the left orbit.
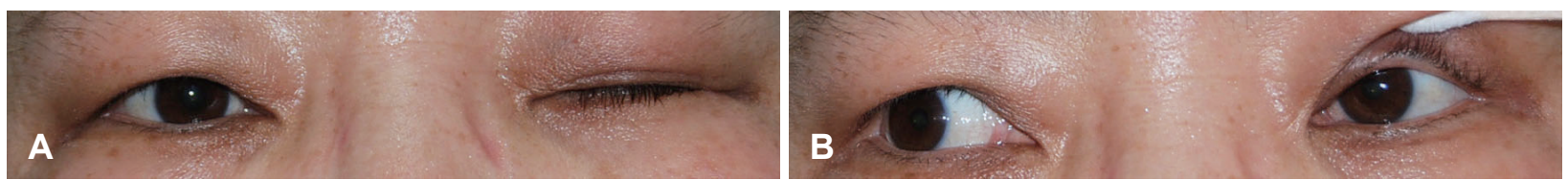

Fig. 3. Left side blepharotosis that developed after surgery. Straight gaze (A) and gaze to the right (B).

주시 때 좌측 내직근으로 추정되는 외안근 장애도 관찰되었 다. 수술 후 5년이 지났으나 안검하수 및 외안근 장애는 호전 되지 않았다.

\section{고 찰}

1980년대에 Kennedy와 Stammberger에 의한 내시경 부비 동 수술 도입 후, 현재 내시경 부비동 수술은 다양한 부비동 질환에 시행되는 흔한 수술 방법이 되었다. 하지만 내시경 수 술은 수술 중 해부학적 위치와 내시경으로 보이는 상 사이의 차이가 있을 경우 합병증 발생 가능성이 높아진다. 특히, 사 골동 병변 수술 시 안구와 인접해 있는 특성으로 인해 안과 적 합병증이 발생할 가능성이 항상 잠재되어 있다.") 또한, 재 수술의 경우 정상적인 해부학적 지표의 소실로 인하여 합병 증이 발생할 가능성이 더 커지며, 미세흡입절삭기의 사용 및 출혈로 인한 명확한 수술 시야 확보의 어려움도 한 요인이 될 수 있다. ${ }^{10-12)}$ 본 증례에서도 이전 수술로 인하여 해부지표의 변형이 있었으며 뇌경색 재발 방지 목적으로 항응고제를 복 용하던 투약력이 있어 출혈 경향이 있었다.

하지만 내시경 부비동 수술의 합병증으로 발생한 안검하수 는 거의 보고된 바가 없다. 본 증례에서는 부비동 수술 후 안
와의 내측벽의 일부 손상과 동반된 관련 신경(3번 뇌신경)의 손상 혹은 마비, 주변조직(외안근)의 미세 손상 및 이로 인한 출혈과 부종에 기인한 것으로 보인다.

3 번 뇌신경은 눈꺼풀의 올림과 함께 안구의 상전, 내전, 하 전과 동공 반사에 관여하는데 머리 안쪽에서부터 출발하여 안와 내에서 위분지와 아래분지로 나뉘고, 윗분지가 다시 눈 꺼풀 올림근을 지배하는 분지와 안구의 상전을 담당하는 상 직근을 지배하는 분지로 나뉜다.

본 증례의 경우 윗눈꺼풀 부종은 심하지 않으면서 상전 안 구운동의 제한이 나타나지 않았으므로 상직근의 기능은 보 존되어 있어, 3 번 뇌신경의 위분지 중에서 눈꺼풀올림근에만 분포하는 말단분지만 손상 또는 마비가 발생한 것으로 보이 며, 수술 시 가해진 힘에 의한 국소적 좌상 또는 주변 조직 출 혈과 부종 등에 의한 압박으로 신경으로의 혈액공급이 중단 되어 발생한 허혈성 손상으로 의심된다. ${ }^{13)} \mathrm{Chan}$ 등 ${ }^{14}$ 은 한쪽 전두사골동염에 의해서 생긴 안검하수를 보고한 바 있으며 해당 증례는 부비동염 치료 후 안검하수가 호전되었었다.

3 번 뇌신경의 손상 또는 마비가 어느 정도 회복되는지 최소 6개월의 경과 관찰이 필요하며,5) 이후에도 증상이 호전되지 않을 시 안검하수는 눈꺼풀 수술 통한 교정을 고려해 볼 수 있으나 예후가 양호하지 않다. 따라서 이러한 안구 합병증이 
생길 수 있는 가능성에 대해 염두에 두고 최대한 합병증이

생기지 않도록 노력해야 한다.

\section{Acknowledgments}

None.

\section{Author Contribution}

Conceptualization: Hwikyeong Jung, Kyubo Kim. Data curation: Geonwoo Kim. Investigation: Jaesoon Kim. Supervision: Kyubo Kim. Writing — original draft: Hwikyeong Jung. Writing—review \& editing: Hwikyeong Jung, Kyubo Kim.

\section{ORCID}

Kyubo Kim

https://orcid.org/0000-0002-6452-1791

\section{REFERENCES}

1) Lund VJ, Wright A, Yiotakis J. Complications and medicolegal aspects of endoscopic sinus surgery. J R Soc Med 1997;90(8):422-8.

2) May M, Levine HL, Mester SJ, Schaitkin B. Complications of endoscopic sinus surgery: Analysis of 2108 patients--incidence and prevention. Laryngoscope 1994;104(9):1080-3.

3) Seredyka-Burduk M, Burduk PK, Wierzchowska M, Kaluzny B, Malukiewicz G. Ophthalmic complications of endoscopic sinus surgery. Braz J Otorhinolaryngol 2017;83(3):318-23.

4) Stankiewicz JA, Lal D, Connor M, Welch K. Complications in endoscopic sinus surgery for chronic rhinosinusitis: A 25 -year experience. Laryngoscope 2011;121(12):2684-701.
5) Siedek V, Pilzweger E, Betz C, Berghaus A, Leunig A. Complications in endonasal sinus surgery: A 5-year retrospective study of 2,596 patients. Eur Arch Otorhinolaryngol 2013;270(1):141-8.

6) Bhatti MT, Stankiewicz JA. Ophthalmic complications of endoscopic sinus surgery. Surv Ophthalmol 2003;48(4):389-402.

7) Corey JP, Bumsted R, Panje W, Namon A. Orbital complications in functional endoscopic sinus surgery. Otolaryngol Head Neck Surg 1993;109(5):814-20.

8) Bhatti MT. Neuro-ophthalmic complications of endoscopic sinus surgery. Curr Opin Ophthalmol 2007;18(6):450-8.

9) Han JK, Higgins TS. Management of orbital complications in endoscopic sinus surgery. Curr Opin Otolaryngol Head Neck Surg 2010;18(1):32-6.

10) Bhatti MT, Giannoni CM, Raynor E, Monshizadeh R, Levine LM. Ocular motility complications after endoscopic sinus surgery with powered cutting instruments. Otolaryngol Head Neck Surg 2001; 125(5):501-9.

11) Rene C, Rose GE, Lenthall R, Moseley I. Major orbital complications of endoscopic sinus surgery. Br J Ophthalmol 2001;85(5):598-603.

12) Asaka $D$, Nakayama $T$, Hama $T$, Okushi $T$, Matsuwaki $Y$, Yoshikawa $\mathrm{M}$, et al. Risk factors for complications of endoscopic sinus surgery for chronic rhinosinusitis. Am J Rhinol Allergy 2012;26(1):61-4.

13) Díaz-Manera J, Luna S, Roig C. Ocular ptosis: Differential diagnosis and treatment. Curr Opin Neurol 2018;31(5):618-27.

14) Chan LW, Lin CW, Hsieh YT. Superior divisional oculomotor nerve palsy caused by fronto-ethmoidal sinusitis. Can J Ophthalmol 2018;53(4):e138-40.

15) Wu H, Shen T, Chen J, Yan J. Long-term therapeutic outcome of ophthalmic complications following endoscopic sinus surgery. Medicine (Baltimore) 2016;95(38):e4896. 